\title{
Modeling and Study of a Standalone PMSG Wind Generation System Using MATLAB/SIMULINK
}

\author{
Mohammed Aslam Husain", Abu Tariq \\ Department of Electrical Engineering, Aligarh Muslim University (AMU), Aligarh, India \\ *Corresponding Author: mahusain87@gmail.com
}

Copyright $($ C 2014Horizon Research Publishing All rights reserved

\begin{abstract}
The paper presents the modeling and performance analysis of a standalone wind system in MATLAB/SIMULINK environment. Stand-alone systems using renewable energy sources, such as wind energy with storage battery banks are commonly used to supply remote houses. The model of wind turbine is developed using basic circuit equations governing the operation of the wind turbine. Permanent Magnet Synchronous Generator (PMSG), which is based on variable-speed operation, has been used in this paper. Since the speed of wind turbine is variable, the generator is controlled by power electronic devices. A rectifier is used to rectify the output voltage of PMSG and $\mathrm{DC} / \mathrm{DC}$ buck converter is used to decrease this rectified voltage to that of battery and connected DC load. The buck converter is controlled to extract the maximum power output of wind system. Firstly the mathematical modeling of a wind turbine is done and its different characteristics have been obtained for different parameters. Secondly a standalone model of wind system is modeled and analyzed. This paper is useful to model, simulate and study the effect of change in wind speed of a standalone wind system.
\end{abstract}

Keywords Turbine, PMSG, Wind Speed, MATLAB Simulation

\section{Introduction}

Standalone Wind generation system offers a feasible solution to distributed power generation for isolated localities where utility grids are not available. It is also free from pollution what makes it more attractive. For isolated localities, one practical approach to self-sufficient power generation involves using a wind turbine with battery storage to create a stand-alone system $[1,2]$.

The common types of AC generator that are possible candidates in modern wind turbine systems are as follows: Squirrel-Cage rotor Induction Generator; Wound-Rotor Induction Generator; Doubly-Fed Induction Generator; Synchronous Generator (With external field excitation); and
Permanent Magnet Synchronous Generator [3]. However, in this paper the variable-speed directly-driven multi-pole permanent magnet synchronous generator (PMSG) wind architecture is chosen for this purpose, it offers better performance due to higher efficiency and less maintenance because it does not have rotor current. PMSG can be used without a gearbox, which implies a reduction of the weight of the nacelle and reduction of costs [1].

The main task of this paper is to develop a simulation model of a standalone PMSG Wind generation System using MATLAB/SIMULINK system. Characteristics of modeled wind turbine and standalone wind system have been shown for different conditions. This paper includes in details the equations that form the wind turbine. The aim of this paper is to provide the reader with all necessary information to develop wind turbine models and circuits that can be used in the simulation for a standalone wind generation system.

\section{Modeling of Wind Turbine}

Present The power captured from the wind turbine is given bythe equation (1) $[1,2,9]$.

$$
\mathrm{P}_{\mathrm{w}}=1 / 2 \mathrm{C}_{\mathrm{p}} \rho \mathrm{AV}_{\mathrm{w}}{ }^{3}
$$

Where $C_{p}$ is the power coefficient, $\rho$ is the air density, which is equal to $1.225 \mathrm{~kg} / \mathrm{m}^{3}, \mathrm{~V}_{\mathrm{w}}$ is the wind speed in $\mathrm{m} / \mathrm{s}$ and $\mathrm{A}$ is the area swept by the rotor in $\mathrm{m}^{2}$.

The volume of aerodynamic torque $T_{w}$ in N-m is given by the ratio between the power from the wind and the turbine rotor speed $\mathrm{w}_{\mathrm{w}}$ in $\mathrm{rad} / \mathrm{s}$, as follows

$$
\mathrm{T}_{\mathrm{w}}=\mathrm{P}_{\mathrm{w}} / \mathrm{w}_{\mathrm{w}}
$$

Mechanical torque transferred to the generator is equal to the aerodynamic torque since there is no gearbox. The power coefficient $\mathrm{Cp}$ has its maximum value equal to 0.593 which means that the power extracted from the wind is at all times less than $59.3 \%$ (Betz's limit), this is because of the various aerodynamic losses depending on rotor construction. The common function defining the power coefficient as a function of the tip speed ratio and the blade pitch angle is given as 


$$
C p(\lambda, \vartheta)=c_{1}\left(c_{2} \frac{1}{\beta}-c_{3} \vartheta-c_{4} \vartheta^{x}-c_{6}\right) e^{-c_{5} / \beta}
$$

Since this function depends on the wind turbine rotor type, the coefficient $c_{1}-c_{6}$ and $x$ can be different for various turbine designs. The coefficients are equal to: $\mathrm{c}_{1}=0.5, \mathrm{c}_{2}=116, \mathrm{c}_{3}=0.4, \mathrm{c}_{4}=0, \mathrm{c}_{5}=5, \mathrm{c}_{6}=21$ ( $\mathrm{x}$ is not used because $\mathrm{c}_{4}=0$ ). Furthermore the parameter is also defined as

$$
\frac{1}{\beta}=\frac{1}{\lambda+0.08 \vartheta}-\frac{0.035}{1+\vartheta 3}
$$

Where $\vartheta$ is the pitch angle and the tip speed ratio $\lambda$ is defined as

$$
\lambda=\mathrm{w}_{\mathrm{w}} \mathrm{R} / \mathrm{V}_{\mathrm{w}}
$$

Where $\mathrm{R}$ is the rotor radius $[\mathrm{m}], \mathrm{w}_{\mathrm{w}}$ is the angular velocity of rotor $[\mathrm{rad} / \mathrm{s}]$ and $\mathrm{V}_{\mathrm{w}}$ is wind speed $[\mathrm{m} / \mathrm{s}][1,2,9]$.

The model of the wind turbine realised in Simulink as shown in figure 1 and the figure 2 shows the mask of wind turbine $[4,6,9]$.

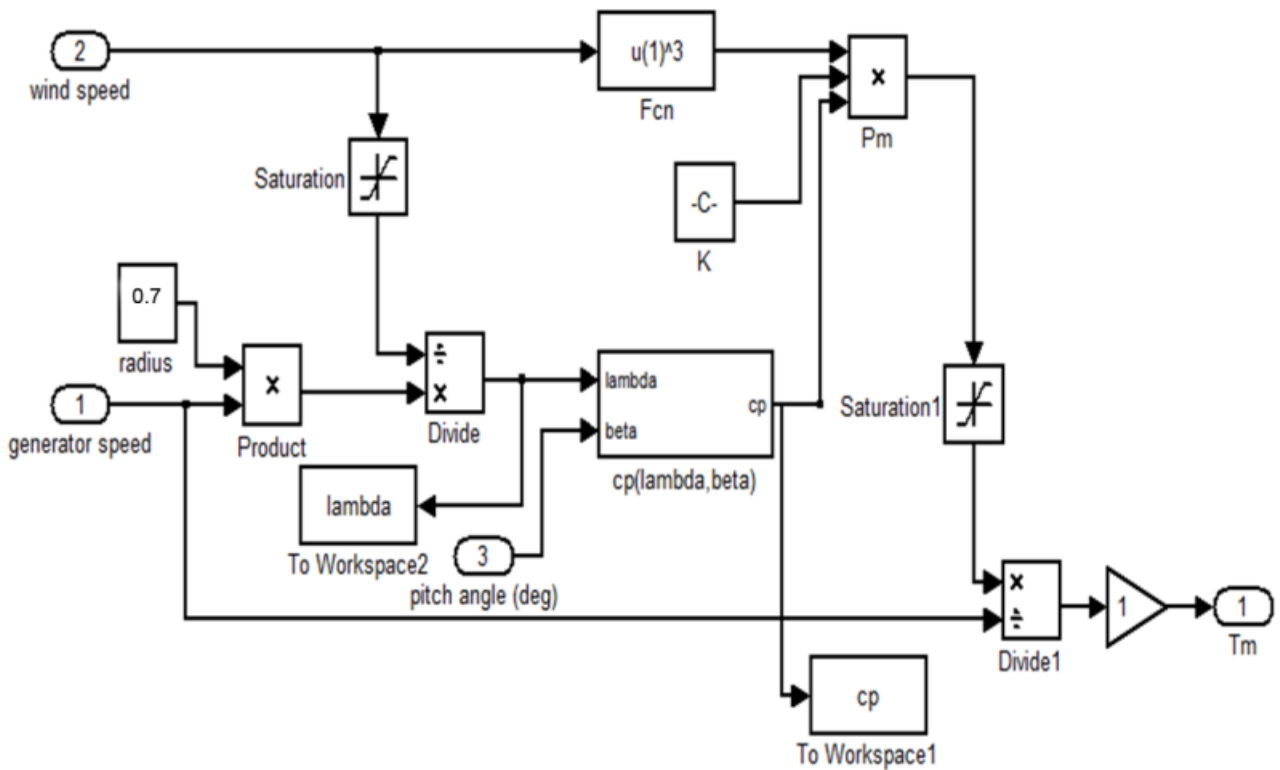

Figure 1. Wind Turbine model

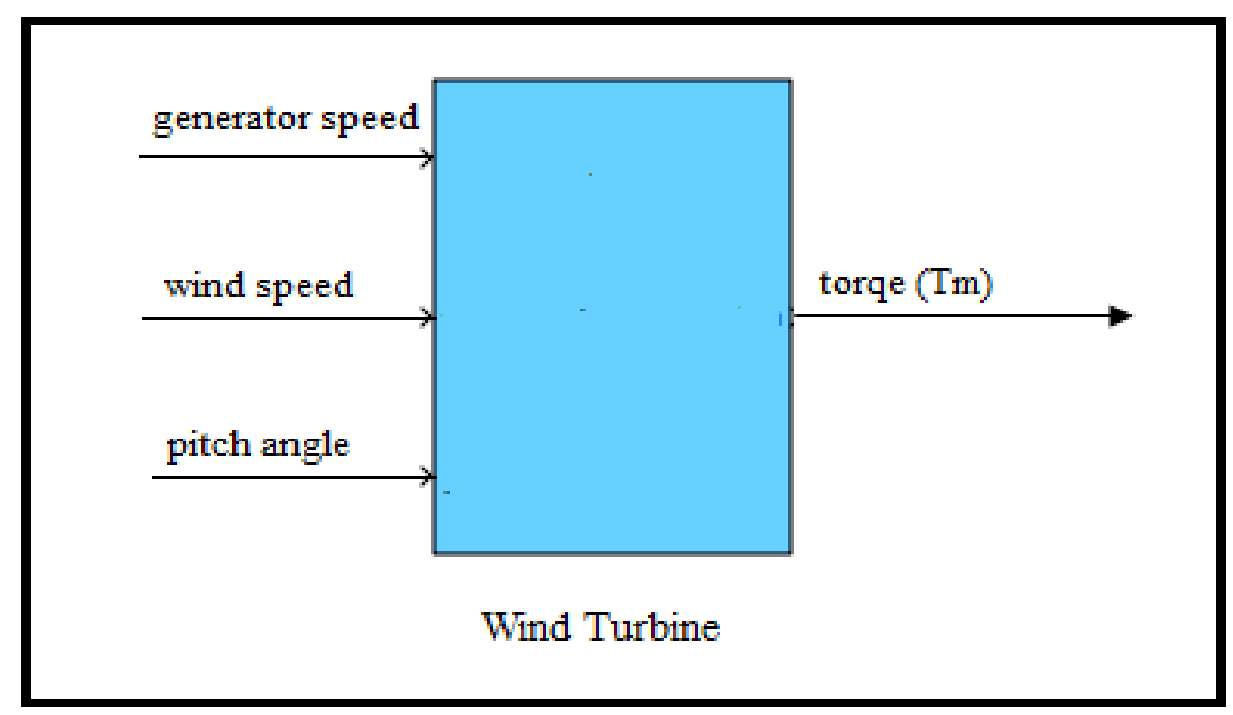

Figure 2. Mask of Wind Turbine

Input to the wind turbine is generator speed, wind speed and pitch angle and output is the torque which is given to drive the generator. Figure 3 represents the simulation results of power coefficient versus tip speed ratio characteristics for several blade pitch angle, figure 4 plots the power speed curves for various wind speeds and figure 5 shows the torque speed curves for different wind speed. 


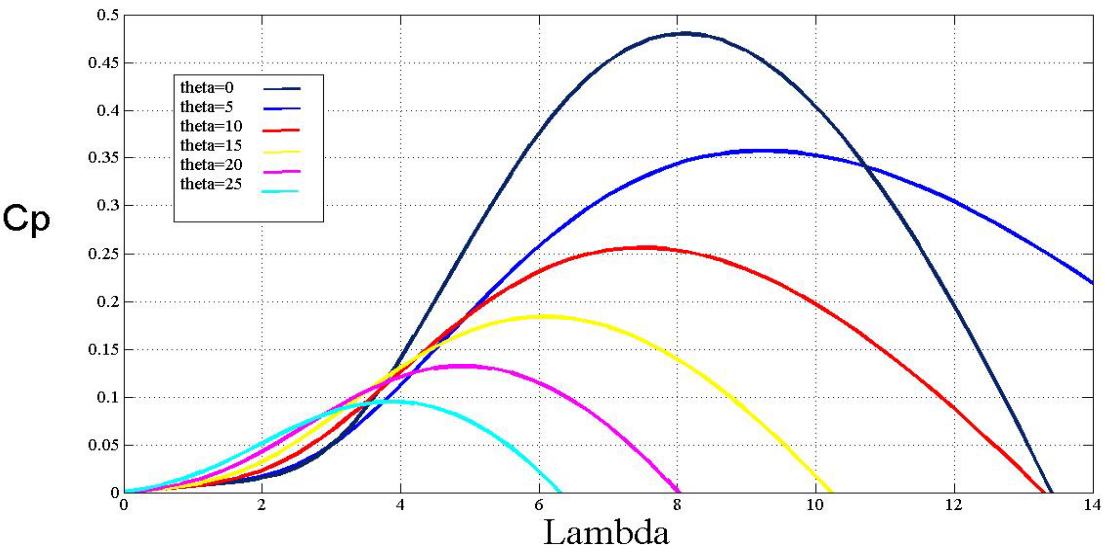

Figure 3. Cp vs. Lambda characteristics for various blade pitch angle

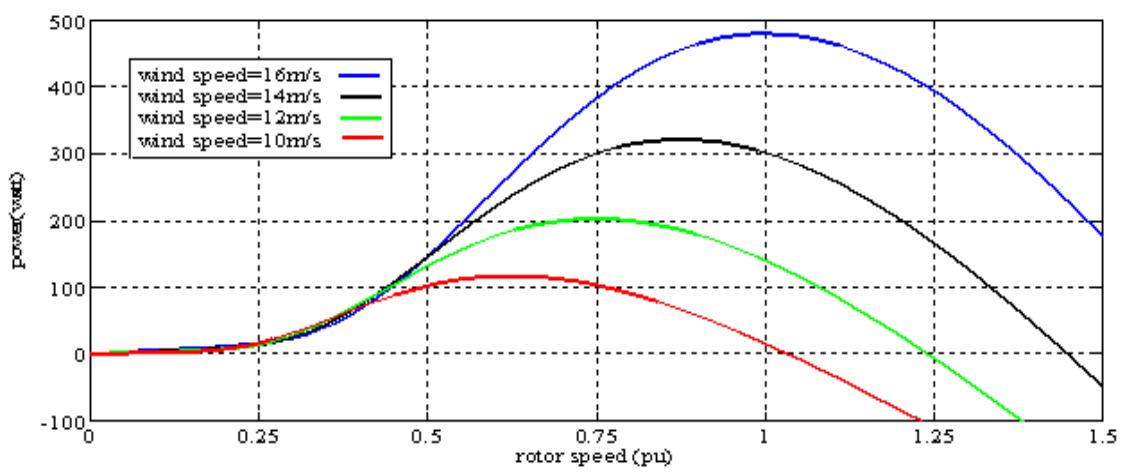

Figure 4. Power vs. speed curves for different wind speeds

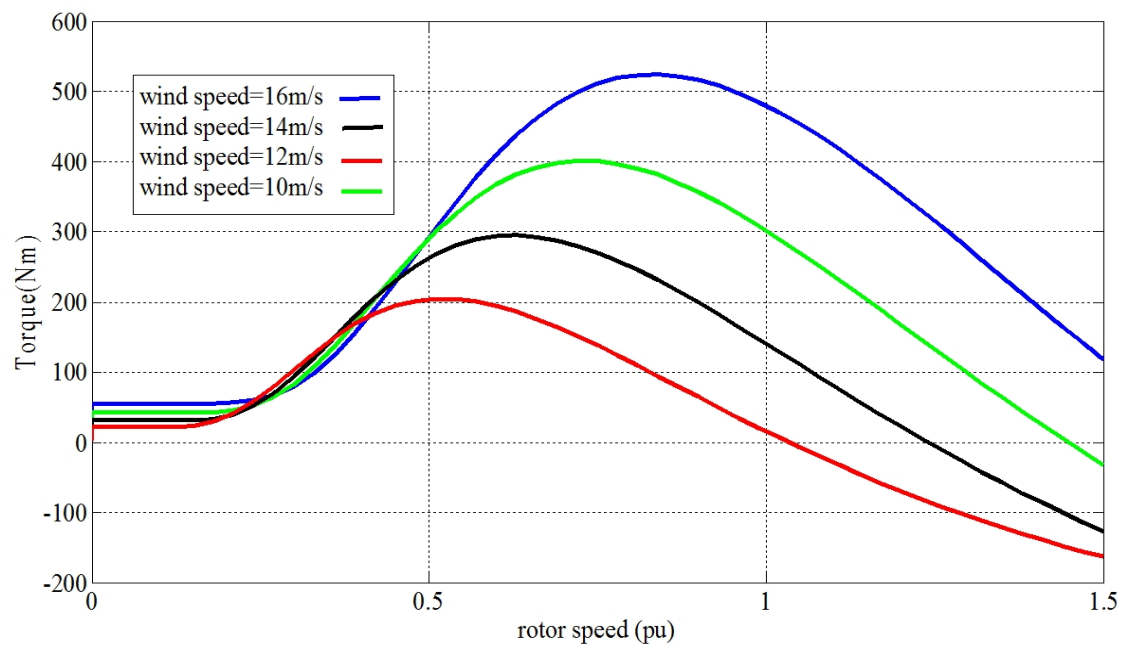

Figure 5. Torque vs. speed curves for different wind speeds

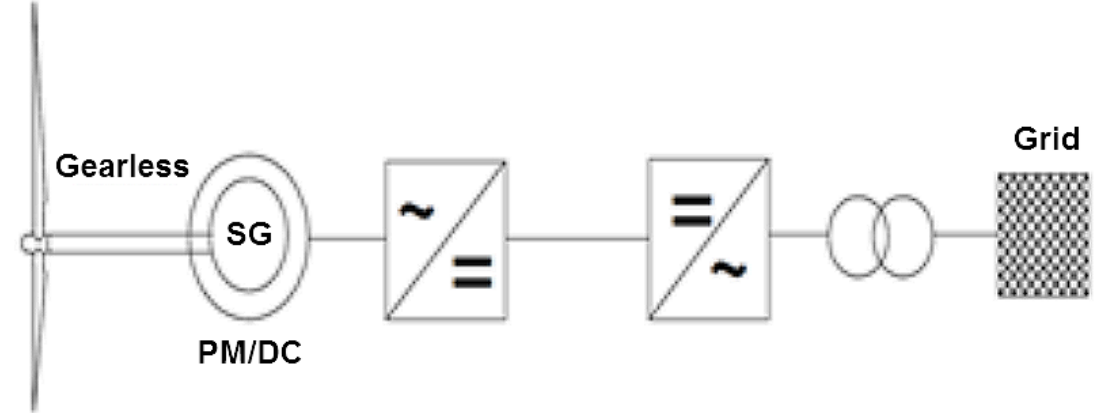

Figure 6. Gearless PMSG with full-scale converter 


\section{PMSG Driven System}

The direct driven wind turbine concept with multi-pole permanent magnet synchronous generator (PMSG) and full-scale frequency converter is a promising but not yet very popular wind turbine concept for modern wind turbines. The gearless PMSG with full-scale converter is as shown in Figure 6.

As a gearbox causes greater weight, losses, costs and demands maintenance, a gearless structure represents an efficient and robust answer, which could be very favorable especially for offshore applications. Moreover, due to the permanent magnet excitation of the generator the DC excitation system can be eliminated, decreasing again weight, losses, costs and maintenance requirements. The efficiency of a PMSG wind turbine is thus assessed to be higher than for other concepts. However, the disadvantages of the permanent magnet excitation are the still high costs for permanent magnet materials and a fixed excitation, which cannot be varied according to the working condition requirement. As multi-pole permanent magnet generators are low speed applications and generally connected to the grid using a frequency converter system, the generator has no damper winding in the rotor core. Moreover, due to the permanent excitation a PMSG has no field windings, in which transient currents could be induced or damped respectively.

Hence, in case of load changes the field windings would not contribute to damping either. As neither a damper nor field winding exists in a PMSG, no transient or sub-transient reactance can be defined for the PMSG.

$$
\begin{aligned}
& \text { i.e. } \\
& \mathrm{X}_{\mathrm{d}}=\mathrm{X}_{\mathrm{d}^{\prime}}=\mathrm{X}_{\mathrm{d}}{ }^{\prime \prime} \\
& \mathrm{X}_{\mathrm{q}}=\mathrm{X}_{\mathrm{q}}{ }^{\prime}=\mathrm{X}_{\mathrm{q}}^{\prime \prime} \\
& \text { where } \\
& \mathrm{X}_{\mathrm{d}} \text { and } \mathrm{X}_{\mathrm{q}} \quad \text {-synchronous reactance } \\
& \mathrm{X}_{\mathrm{d}}{ }^{\prime} \text { and } \mathrm{X}_{\mathrm{q}}{ }^{\prime} \text {-transient reactance } \\
& \mathrm{X}_{\mathrm{d}}{ }^{\prime \prime} \text { and } \mathrm{X}_{\mathrm{q}} \text { " -sub-transient reactance }
\end{aligned}
$$

Nevertheless, as the multi-pole PMSG is used at low speed application with slow dynamics, a damper winding is not as much important. However, damping of the system must then be applied by the use of converter control[7,8,9].

\section{Building the Mathematical Model and Circuit of Wind System with Buck Converter Connected To a Battery and a Load}

DC-DC converter is used to buck the rectified voltage. In the converter circuit the gate receives the pulse from PWM generator. Figure 7 depicts a step-down or a PWM buck converter. It consists of dc input voltage source $\mathrm{V}_{\mathrm{i}}$, boost inductor $\mathrm{L}$, controlled switch $\mathrm{S}$, diode $\mathrm{D}$, filter capacitor $\mathrm{C}$, and load resistance $\mathrm{R}$ [5].

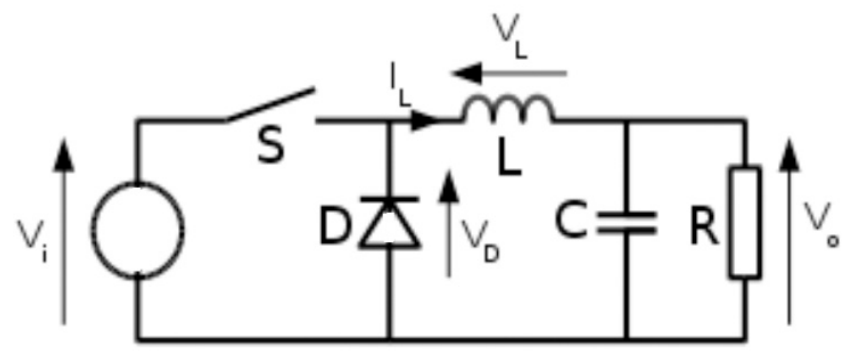

Figure 7. DC-DC buck converter

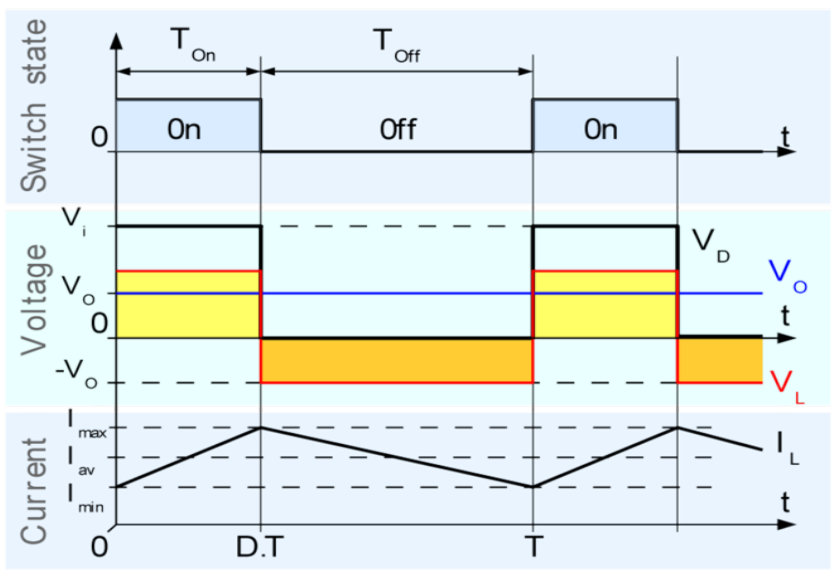

Figure 8. Evolution of the voltages and currents with time in an ideal buck converter operating in continuous mode

A buck converter operates in continuous mode if the current through the inductor $\left(\mathrm{I}_{\mathrm{L}}\right)$ never falls to zero during the commutation cycle. In this mode, the operating principle is described by the plots in figure 2.17:

- When the switch pictured above is closed, the voltage across the inductor is $V_{L}=V_{i}-V_{o}$. The current through the inductor rises linearly. As the diode is reverse-biased by the voltage source $\mathrm{V}$, no current flows through it;

- When the switch is opened, the diode is forward biased. The voltage across the inductor is $V_{L}=-V_{o}$ (neglecting diode drop). Current $\mathrm{I}_{\mathrm{L}}$ decreases.

The overall Simulink model is shown in Figure 9. A $480 \mathrm{~W}, 34$ pole, $300 \mathrm{rpm}$ rated speed, permanent-magnet synchronous generator(PMSG), a diode rectifier and a (DC/DC) buck converter for the tracking of the maximum power point is used in this model. Lead acid battery used here has a nominal voltage rating of $48 \mathrm{~V}[4,5]$.

\section{Simulation Results}

Figures 10, 11, 12, 13 and 14 show different characteristics of the simulated wind system. The variation of output power (Pdc), state of charge (\%SOC), battery terminal voltage and battery current for step change in wind speed from 16 to $12 \mathrm{~m} / \mathrm{s}$ is shown with respect to time in seconds. 


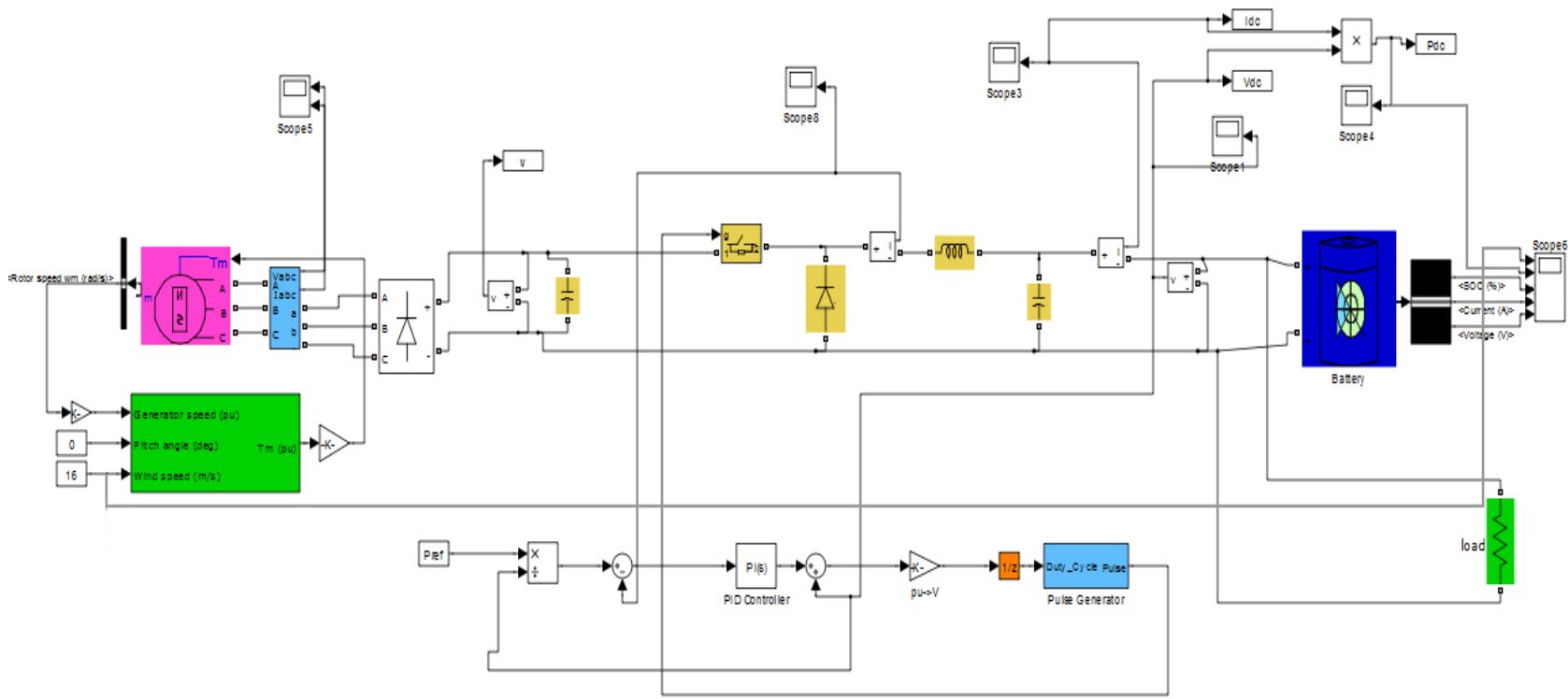

Figure 9. Simulation model of standalone wind system
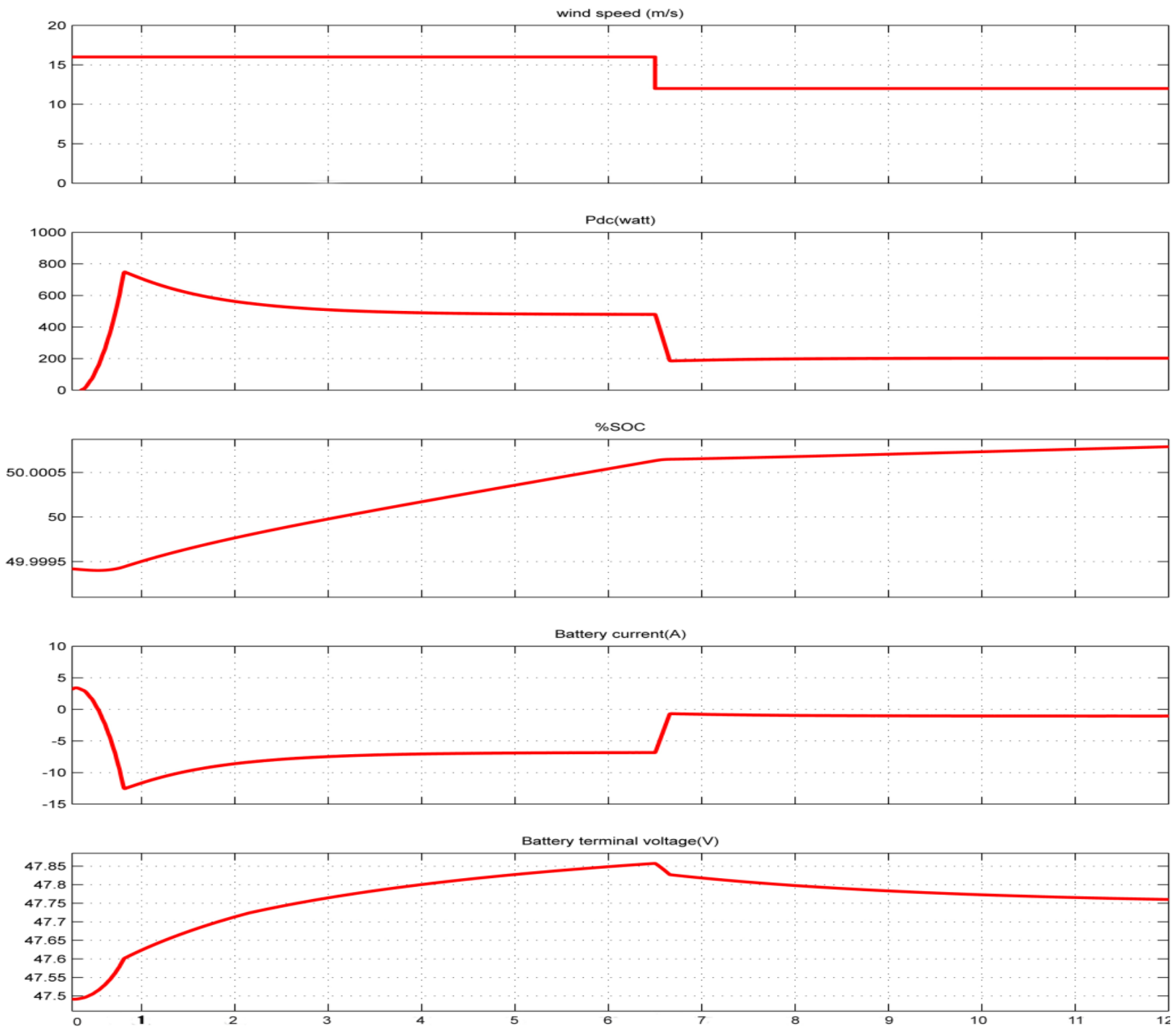

Figure 10. Different characteristics of the simulated wind system for step change in wind speed from $16 \mathrm{~m} / \mathrm{s}$ to $12 \mathrm{~m} / \mathrm{s}$ 


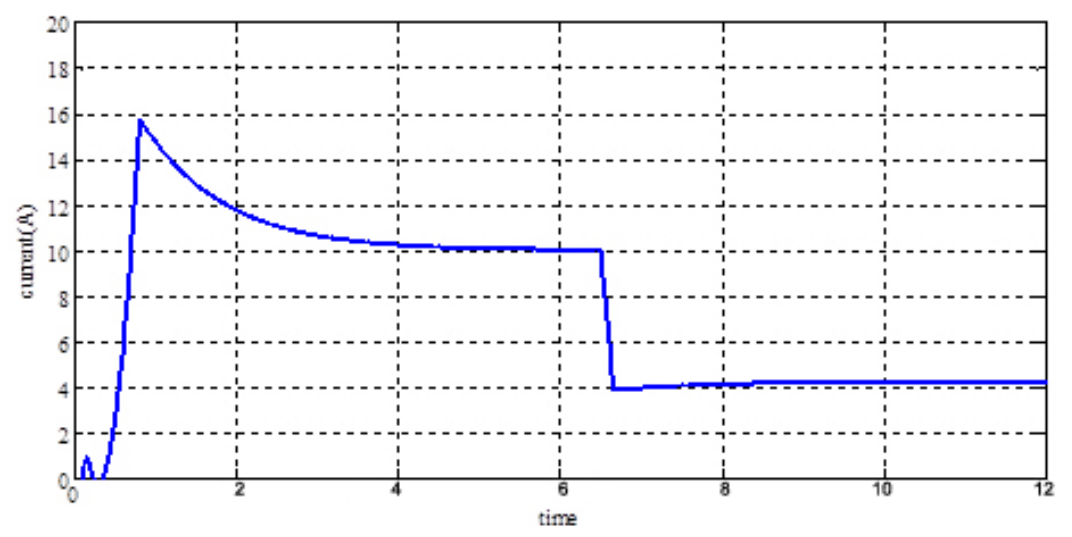

Figure 11. Output current

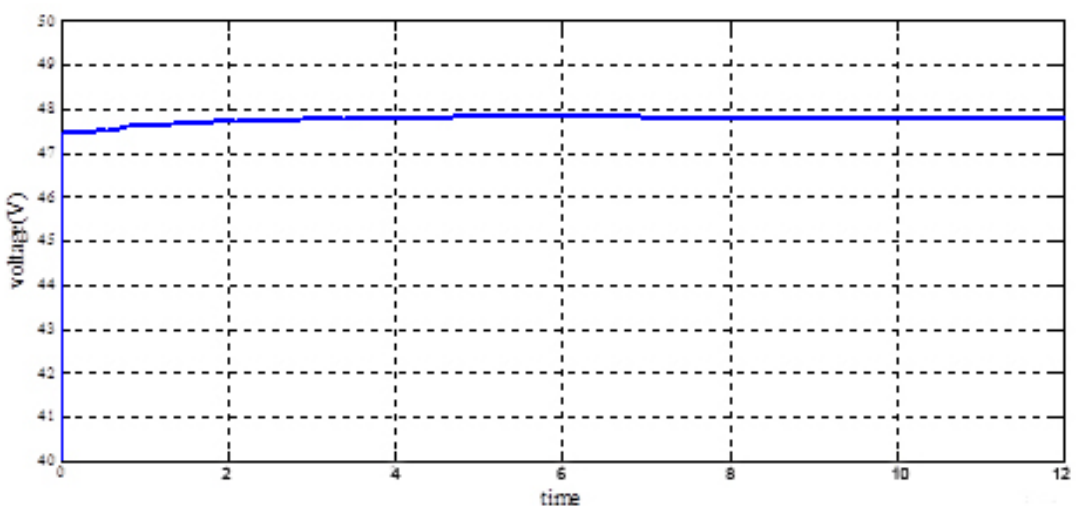

Figure 12. Output Voltage

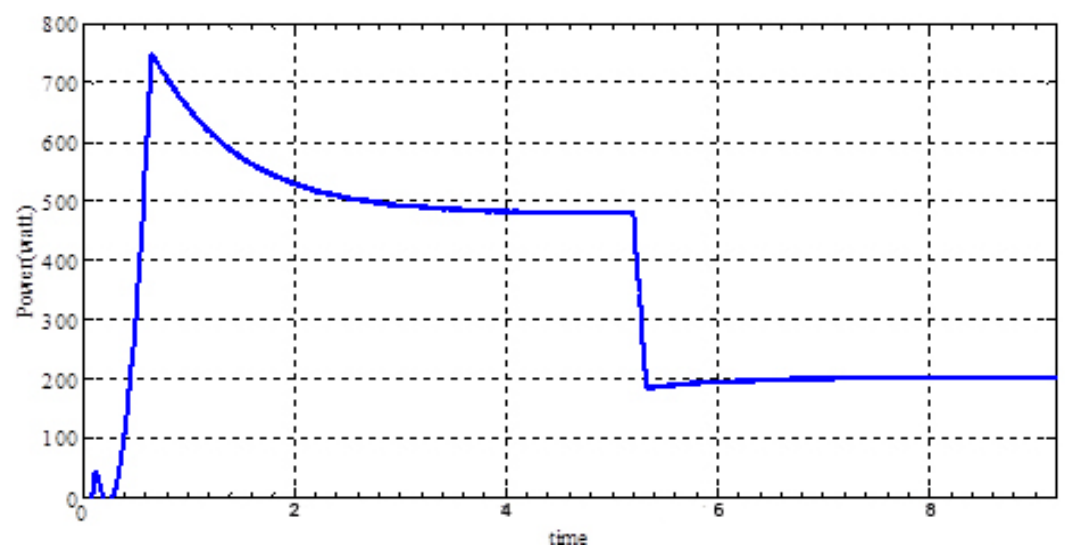

Figure 13. Output power (Pdc) across battery and load

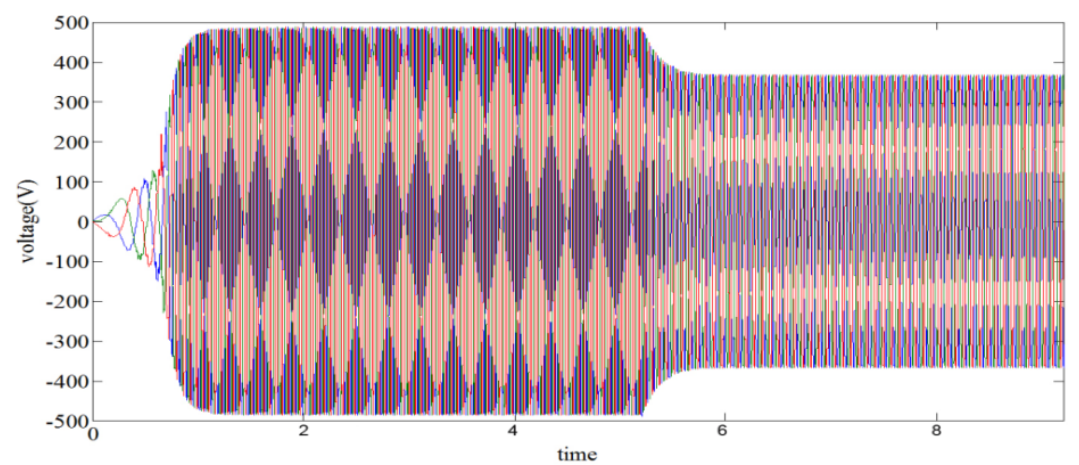

Figure 14. voltage waveforms of wind generator 
In Figure 10, at time $t_{1}=3 \mathrm{sec}$ the system reaches its maximum output power and between $t_{1}$ to $t_{2}(=6.5 \mathrm{sec})$ the output power is 479.8 watts equal to the maximum power (as shown in Figure 4) of the wind system at a wind speed of $16 \mathrm{~m} / \mathrm{s}$.

As the wind speed changes the corresponding value of the output power gets changed. At $t_{2}(=6.5 \mathrm{sec})$ the wind speed changes from 16 to $12 \mathrm{~m} / \mathrm{s}$ and the corresponding value of the output power changes from 479.8 to $202.5 \mathrm{watts}$.

These values are the maximum value of power corresponding to wind speed of 16 and $12 \mathrm{~m} / \mathrm{s}$ respectively. Initially till the output power reaches its maximum value, the battery was feeding the load. But after that, the wind system starts charging the battery and feeds the load.

Also as the value of wind speed decreases to $12 \mathrm{~m} / \mathrm{s}$, the rate of charging reduces as it is clear from the change in value of battery current from 5amperes to less than lamperes.

Figures 11 to 14 show the waveforms of output current, output voltage, output power of the wind system and output voltage of the wind generator respectively for step change in wind speed from 16 to $12 \mathrm{~m} / \mathrm{s}$.

Figure 15 shows different characteristics of the simulated wind system for step change in wind speed from $16 \mathrm{~m} / \mathrm{s}$ to $14 \mathrm{~m} /$ sand then to $10 \mathrm{~m} / \mathrm{s}$.
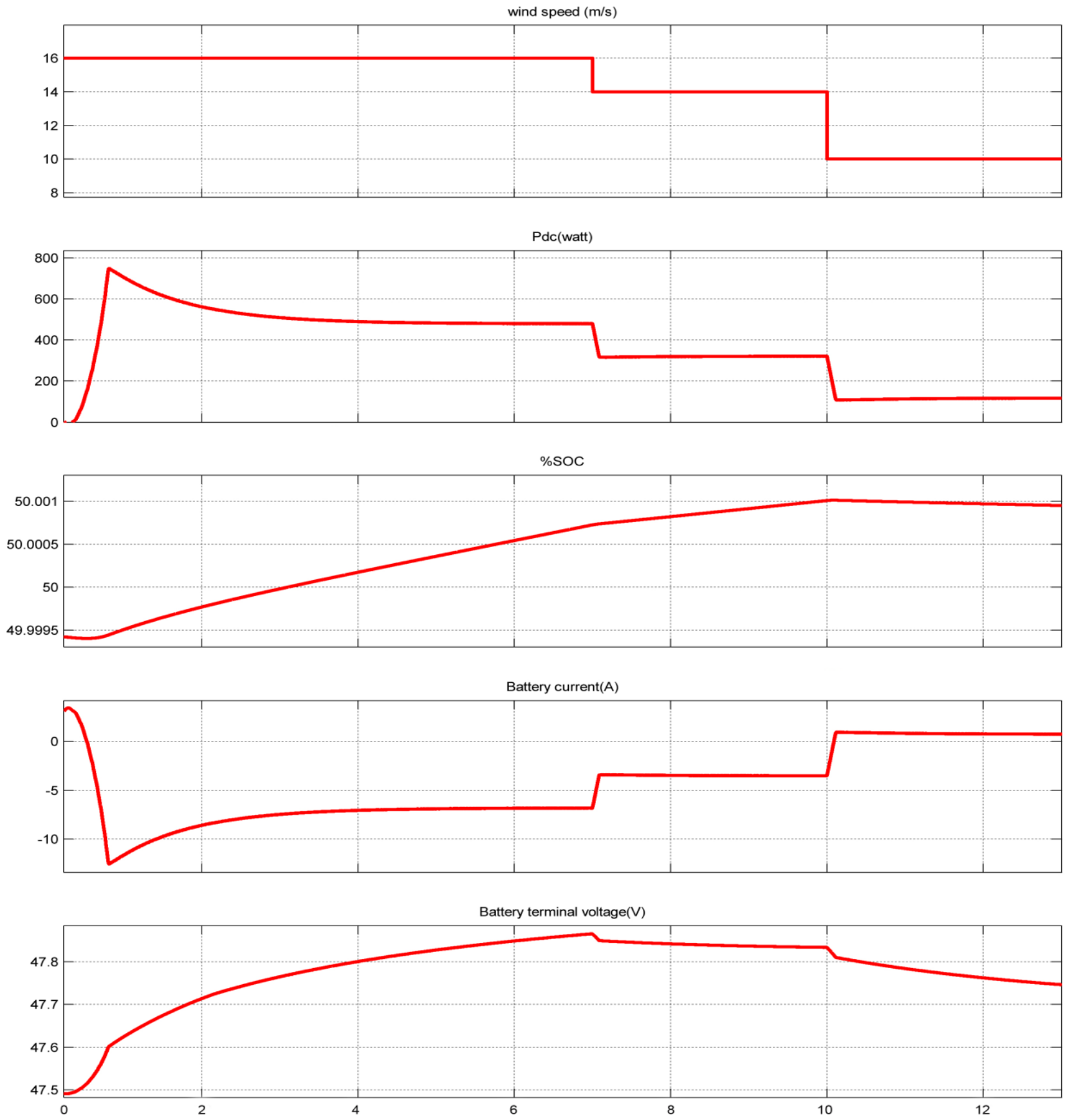

Figure 15. Different characteristics of the simulated wind system for step change in wind speed from $16 \mathrm{~m} / \mathrm{s}$ to $14 \mathrm{~m} / \mathrm{sand}$ then to $10 \mathrm{~m} / \mathrm{s}$ 


\section{Conclusions}

In this paper a SIMULINK model of the wind generation system is proposed and the essential models of the system components were addressed. The model of wind turbine is connected to a PMSG to model a standalone wind power generation system. The rectified output voltage of PMSG is connected to a battery and a load through a dc-dc buck converter and the proposed model is simulated. It is observed that with change in wind speed, the output power of the standalone wind system changes in accordance with the standard results. With additional modification this model can be used for the modelling and study of Grid connected Wind system or hybrid systems.

\section{REFERENCES}

[1] Alejandro Rolan, AlvaroLuna, Gerardo Vazquez, Daniel Aguilar, Gustavo Azevedo, "Modeling of a Variable Speed Wind Turbine with a Permanent Magnet Synchronous Generator ". IEEE International Symposium on Industrial Electronics (ISIE 2009) Seoul Olympic Parktel, Seoul, Korea July 5-8, 2009.

[2] Polinder H., de Haan S. W. H., Dubois M. R., Slootweg J., "Basic Operation Principles and Electrical Conversion Systems of Wind Turbines", NORPIE / 2004, Nordic
Workshop on Power and Industrial Electronics, Paper 069, Trondheim, Norway, 14-16 June, 2004.

[3] MittalR.,Sandhu K. S.and Jain D. K. "Low voltage ride-through (LVRT) of grid interfaced wind driven PMSG," ARPN Journal of Engineering and Applied Sciences., 2009, vol. 4, no. 5. Pp. 73-83.

[4] Dali M., Belhadj, J., Roboam, X. and Blaquiere, J.M. "Control and energy management of a wind photovoltaic hybrid system", Proc. EPE Conference, 2-5 Sept. 2007, pp $1-10$.

[5] Dali M., Belhadj J., Roboam X., "Hybrid solar-wind system with battery storage operating in grid-connected and standalone mode: Control and energy management Experimental investigation", Energy 35 (2010) 2587-2595.

[6] Akhmatov V., "Variable-Speed Wind Turbines with Doubly-Fed Induction Generators Part III: Model with the Back-to-back Converters", Wind Engineering, Volume 27, No. 2, pp 79-91, 2003

[7] Hansen A.D., Michalke G., "Modelling and control of variable speed multipole PMSG wind turbine", submitted to Wind Energy, 2007.

[8] Hong-Woo Kima, Sung-SooKimb, Hee-Sang Koa, "Modeling and control of PMSG-based variable-speed wind turbine”, Electric Power Systems Research 80 (2010) 46-52.

[9] Mohammed Aslam Husain and Abu Tariq, "Modeling of a standalone Wind-PV Hybrid generation system using MATLAB/SIMULINK and its performance analysis”. IJSER Volume 4, Issue11, November - 2013. Pp. 1805-1811. 